Website: http://revistas.lamolina.edu.pe/index.php/acu/index

(C) Universidad Nacional Agraria La Molina, Lima - Perú

\title{
Oferta de semen bovino lechero importado y nacional en el Perú del 2003 al 2014
}

\author{
Offer of dairy bovine semen imported and national in Peru from 2003 to 2014
}

\begin{abstract}
Juan Luis Salinas Rivera ${ }^{1 *}$, María Elisa Catalina García Salas ${ }^{2}$, Marcia Graciela Cárdenas Medina ${ }^{1}$, Próspero Celestino Cabrera Villanueva ${ }^{3}$, Agustín Eugenio Pallete Pallete ${ }^{4}$, Justo Germán Rodríguez Franco ${ }^{3}$, Jonathan Alejandro Morón Barraza $^{3}$
\end{abstract}

* Autor de correspondencia

\begin{abstract}
Resumen
El objetivo del presente estudio fue determinar la oferta de pajillas de semen bovino lechero importado y nacional en el Perú de los años 2003 al 2014, el trabajo se realizó en el Programa de Mejoramiento Animal de la Universidad Nacional Agraria La Molina (UNALM). Se usó la información de los expedientes físicos oficiales de cada importación de semen bovino, del Servicio Nacional de Sanidad Agraria y de los archivos de la oficina del Banco Nacional de Semen (BNS) de la UNALM. Se trabajó con el total de pajillas importadas por cada año, determinando las razas, los países de origen y las empresas comerciales que exportaron el material genético; y con el total de pajillas nacionales colocadas en el mercado nacional, determinando las cantidades y proporciones de pajillas por razas y regiones donde fueron distribuidas. El software MS Excel 2010 fue utilizado para el procesamiento y análisis de datos. La oferta total de pajillas importadas en el período de 12 años fue de 2510 079, de 5765 bovinos de 15 razas lecheras provenientes de 12 países de tres continentes, solicitadas a 42 empresas comerciales y la oferta total de BNS de pajillas nacionales fue 1111290 , para el mismo período. Se concluye que la oferta anual de semen importado es mayor que el semen nacional, la primera tuvo un crecimiento promedio de $11,1 \%$ el cual fue sostenido en el período y la segunda un menor crecimiento del 4,9\%, lo cual ha generado una gran brecha y al año 2014 una proporción de tres pajillas importadas por 1 nacional. Además esta oferta total de semen solo cubre un 5,1\% de las necesidades en inseminación artificial de las vacas aptas para inseminación.
\end{abstract}

Palabras clave: bovino; leche; semen; pajillas; importaciones; oferta; distribución.

\begin{abstract}
The objective of the present study was to determine the supply of straws of imported and national dairy cattle semen in Peru from 2003 to 2014, the work was carried out in the Animal Improvement Program of the National Agrarian University La Molina (UNALM). Information was used on the official physical records of each importation of bovine semen, the National Agrarian Health Service and the archives of the National Semen Bank of the UNALM. We worked with the total number of straws imported each year, determining the races, the countries of origin and the commercial companies that exported the genetic material; And with the total of national straws placed in the national market, determining the quantities and proportions of straws by races and regions where they were distributed. MS Excel 2010 software was used for data processing and analysis. The total supply of straws imported during the 12-year period was 2510079 , of 5765 cattle from 15 dairy breeds from 12 countries on three continents, requested from 42 commercial enterprises and the total BNS supply of domestic straws was 1111 290, for the same period. It is concluded that the annual supply of imported semen is higher than the national semen, the first had an average growth of $11,1 \%$, which was sustained in the period and the second one, a lower growth of $41,9 \%$, which has generated a large gap and by 2014 a proportion of three straws imported per 1 national. In addition, this total supply of semen only covers $5.1 \%$ of the artificial insemination needs of the cows suitable for inseminate.
\end{abstract}

Keywords: Bovine; milk; semen; straws; imports; supply; distribution.

\section{Introducción}

En la actualidad, está masificado el uso del semen congelado mediante la técnica de la inseminación artificial, debido a que el ganadero espera incrementar la productividad de leche usando reproductores seleccionados genéticamente (Cabrera y Pantoja, 2012). La industria de la producción de semen congelado ha sido impulsada por el comercio internacional, y las exportaciones a diferentes países han ido creciendo exponencialmente estos últimos años (Funk, 2006). Estados Unidos, Canadá dominan el mercado mundial de semen congelado bovino. Los dos países exportan el 57\% de la oferta internacional (United Nation Statistics Division, 2014). Ellos y otros países europeos son los principales exportadores de genética lechera, especialmente de pajillas de bovinos de raza Holstein, Brown Swiss y Jersey.

\footnotetext{
*Investigador Independiente, Lima, Perú.

${ }^{2}$ Facultad de Zootecnia, Universidad Nacional Agraria La Molina, Lima, Perú. E-mail: megarcia@lamolina.edu.pe

${ }^{3}$ Facultad de Zootecnia, Universidad Nacional Agraria La Molina, Lima, Perú. E-mail: pcavi@lamolina.edu.pe; grodriguez@lamolina.edu.pe

${ }^{4}$ Facultad de Zootecnia, Universidad Nacional Agraria La Molina, Lima, Perú. E-mail: aep@lamolina.edu.pe
} 
El semen de un reproductor perteneciente a una raza o a una específica línea de sangre es comercializado mundialmente. Esto es especialmente importante en países que han introducido razas y buscan ampliar el número de descendientes con una genética mejorada (Heise, 2012). Etcheverry (2009) indica que más del 90\% de exportaciones de genética bovina se realiza a países sudamericanos. Se puede dividir a estos en dos grandes bloques: MERCOSUR (Brasil, Uruguay y Paraguay) y Comunidad Andina (Bolivia, Ecuador, Colombia, Venezuela, Chile y Perú). Los diez primeros exportadores de semen congelado por volumen de dinero, son EE.UU., Canadá, países de la Unión Europea y Australia, seguidos por Uruguay y Nueva Zelanda. Estos países al ser los principales productores de semen congelado en el mundo, tienen distintas empresas genéticas que exportan las pajillas de semen de bovinos de leche y también de carne.

Nuestra ganadería forma parte de este mercado internacional. El Perú pertenece a una cadena comercial que va en ascenso. Durante los últimos años se importa semen bovino de distintas empresas genéticas en el mundo, principalmente de América y Europa, dependiendo del objetivo de producción del ganadero. Así mismo, el Perú desde 1982 cuenta con un Banco Nacional de Semen (BNS) administrado por la UNALM, que selecciona sementales de distintos zonas geográficas del país para ofrecer una genética de calidad adaptada a nuestras condiciones de manejo, brindando un producto accesible a los ganaderos nacionales. El principal distribuidor de semen nacional es el Banco Nacional de Semen de la Molina, utilizando exclusivamente toros jóvenes de las mejores ganaderías lecheras (Pallete, 2001).

Aunque las importaciones han ido en aumento como lo indican las tesis de Salinas (2016) y Cárdenas (2010), en los últimos años no contamos con una institución oficial que consolide las estadísticas del total de semen que ingresa al país, de qué país provienen y las razas lecheras que se usan los ganaderos. Se desconoce también si el total de pajillas de semen tanto importado como nacional cubre la demanda de nuestra ganadería y si se requiere una mayor o menor oferta. Por lo que, se planteó como objetivo determinar la oferta de pajillas de semen congelado que ingresaron al país vía importaciones oficiales y el total de pajillas nacionales distribuidas por el BNS en los años 2003 al 2014. Los resultados de la investigación nos permiten conocer la situación del mercado de semen bovino lechero, se identificó: a) la oferta de semen congelado anual, la procedencia por país, las razas ofertadas y las empresas genéticas con mayor influencia en el Perú durante el período de estudio y b) el balance de oferta y demanda estimada por la ganadería nacional.

\section{Materiales y métodos}

La investigación se realizó en el Programa de Mejoramiento Animal de la Facultad de Zootecnia de la UNALM. Para obtener la información de importaciones de semen bovino, se coordinó con la institución oficial que autoriza el ingreso de material genético al país: Área de Gestión del Servicio Nacional de Sanidad Agraria (SENASA, 2014) en la sede central La Molina, para acceder a los expedientes físicos de cada importación, correspondientes a las empresas que solicitaron importar semen bovino congelado y cumplieron con los requisitos, los cuales estaban almacenados en la sede Ate Vitarte. De los certificados zoosanitarios oficiales se registró: año de la importación, el nombre del toro, registro genealógico de origen, código de la National Association of Animal Breeders, raza, número de pajillas, empresa genética de procedencia e importador. La comprobación de los datos de los expedientes se realizó con la página web de la Superintendencia Nacional de Aduanas y Administración Tributaria, debido a que es la institución que permite el ingreso al territorio aduanero y luego de cumplir con los derechos arancelarios y obligaciones aduaneras ingresar el producto al país. Y para obtener la información de semen nacional se trabajó con los archivos del Banco Nacional de Semen de la UNALM registrando el nombre del toro, registro genealógico, raza, número de pajillas, departamento de destino.

Para estimar la demanda de pajillas de semen en el ganado vacuno del Perú, se utilizó la población de hembras en etapa fértil, de las diferentes razas presentadas en el último censo agropecuario: CENAGRO 2012 (INEI, 2016), en la Tabla 1 se muestra la población bovina del país por categorías. El número total de hembras aptas para la inseminación artificial (vacas, vaquillas y vaquillonas) fueron de 2911 480. El requerimiento teórico de número de pajillas por inseminación artificial para lograr una hembra preñada es de 2,41 servicios por concepción según Ortiz (2006), en establos de cuenca lechera de Lima y Mellisho et al. (2003) indican valores de 1,7 a 2,3 pajillas en MajesArequipa.

Tabla 1. Distribución del ganado vacuno por razas y categorías CENAGRO - 2012

\begin{tabular}{|c|c|c|c|c|c|c|}
\hline Categoría & Holstein & $\begin{array}{c}\text { Brown } \\
\text { Swiss } \\
\end{array}$ & $\begin{array}{l}\text { Gyr/ } \\
\text { Cebú }\end{array}$ & $\begin{array}{l}\text { Otras } \\
\text { Razas }\end{array}$ & Criollo & Total \\
\hline $\begin{array}{c}\text { Terneros y } \\
\text { terneras }\end{array}$ & 129665 & 219093 & 37696 & 57406 & 707853 & 1151713 \\
\hline Vaquillas & 50497 & 84222 & 17632 & 22435 & 282659 & 457445 \\
\hline Vaquillonas & 44979 & 71615 & 17786 & 19500 & 250517 & 404397 \\
\hline Vacas & 242411 & 364090 & 60015 & 91785 & 1291337 & 2049638 \\
\hline Toretes & 29013 & 69861 & 18220 & 22966 & 258932 & 398992 \\
\hline Toros & 30968 & 95188 & 20416 & 31485 & 485501 & 663558 \\
\hline Bueyes & - & - & - & - & - & 30301 \\
\hline Total & 527533 & 904069 & 17176 & 45577 & 3276799 & 5156044 \\
\hline
\end{tabular}

La información obtenida se trabajó con el software MS Excel 2010. Determinando lo siguiente: Oferta de pajillas por años, cantidad de pajillas por procedencia de continente y país, oferta de pajillas nacional por región geográfica, distribución de pajillas por razas, oferta de pajillas por empresa genética, y el balance de la oferta y la demanda estimada según la población de vacunos del 
2012, y así conocer la situación del mercado nacional para el semen congelado de bovinos lecheros.

\section{Resultados y discusión}

\section{Oferta de pajillas por años}

En el período 2003-2014 se importó un total de 2510979 pajillas de semen congelado bovino y se distribuyó un total de 1111290 pajillas de semen nacional en el país, la oferta de semen importado fue mayor que la oferta nacional. En la Tabla 2 se muestra la cantidad de pajillas importadas, pajillas nacionales y la tasa de crecimiento en cada año de estudio. Un reporte del Ministerio de agricultura mencionado por Cunliffe (1990), indica que las importaciones de semen se iniciaron en 1957 con 5570 dosis, llegando a 53227 dosis en 1986, en 30 años se había importado 767639 pajillas, con en promedio anual de 25 588 pajillas, después de 23 años en el 2003 se importó 98 516 pajillas, y en el periodo de estudio un promedio de 219 233 pajillas por año.

Tabla 2. Número de pajillas de semen congelado de bovinos lecheros importados y nacionales por años en el Perú-Período 2003-2014

\begin{tabular}{rrrrc}
\hline Año & Importadas & $\begin{array}{c}\text { Tasa de } \\
\text { Crecimiento } \\
(\%)\end{array}$ & Nacionales & $\begin{array}{c}\text { Tasa de } \\
\text { Crecimiento } \\
(\%)\end{array}$ \\
\hline 2003 & 98516 & & 62349 & \\
2004 & 145382 & 47,5 & 84338 & 35,3 \\
2005 & 146815 & 1,0 & 91598 & 8,6 \\
2006 & 160954 & 9,6 & 90405 & $-1,3$ \\
2007 & 173560 & 7,8 & 115981 & 28,3 \\
2008 & 228040 & 31,4 & 129485 & 11,6 \\
2009 & 245346 & 7,6 & 115152 & $-11,1$ \\
2010 & 223931 & $-8,7$ & 84817 & $-26,3$ \\
2011 & 265535 & 18,6 & 81065 & $-4,4$ \\
2012 & 275250 & 3,7 & 81285 & 0,3 \\
2013 & 263339 & $-4,3$ & 82513 & 1,5 \\
2014 & 283411 & 7,6 & 92302 & 11,9 \\
\hline
\end{tabular}

La producción de semen congelado en Perú se inició en 1962 con 3632 dosis, incrementando a 30037 dosis en el año 1986, en el periodo de 24 años se produjo en total de 193654 pajillas, un promedio de 7746 pajillas por año, y después de 23 años en el 2003 su oferta se incrementó a 62349 dosis, con un promedio de 95358 pajillas por año en los 12 años de evaluación. En el misma tabla se puede observar que la tasa de crecimiento anual de oferta de semen importado se incrementa en un promedio de $11,1 \%$, pero tiene fluctuaciones de $47 \%$ a $-8,7 \%$, se presenta una disminución después de un incremento en los años anteriores, probablemente almacenaron semen y los crecimientos fueron mínimos para los siguientes años. Comparando con la tasa de crecimiento de la oferta de semen nacional, esta fue menor de $4,9 \%$, presentando rangos de $35,3 \%$ a $-26,3 \%$, y un periodo negativo de 3 años de decrecimiento, sin embargo, desde el año 2007 al 2009 se observa un pico de crecimiento, esto se debió a que el BNS en estos años firmó un convenio con el Proyecto PRADERA I - Puno, para entregar 17,200 pajillas de semen, después se presentó una disminución en la distribución, y es a partir del 2012 que se decidió implementar nuevas políticas de distribución a provincias y se dio un impulso al crecimiento en los últimos años (Salinas, 2016).

En la Figura 1 se observa la tendencia lineal y positiva de las importaciones, con un coeficiente de regresión de 16384 pajillas por año y coeficiente determinación $\left(\mathrm{R}^{2}\right)$ de 0,92 ; esto nos señala que la oferta de semen importado mostró un crecimiento continuo. Por otro lado, la oferta de pajillas nacionales presenta una tendencia lineal casi estable con un coeficiente de regresión de 301,9 pajillas por año y un $\mathrm{R}^{2}$ de 0,0034 . En los 12 años de estudio se observa que la oferta de semen importado tuvo un crecimiento continuo y creciente, mientras la oferta de semen nacional se mantuvo, esto hace que la brecha se amplíe cada año, lo cual genera una mayor fuga de divisas y es necesario que el BNS tome políticas para mejorar la oferta de sus productos que son en beneficio de la ganadería nacional.

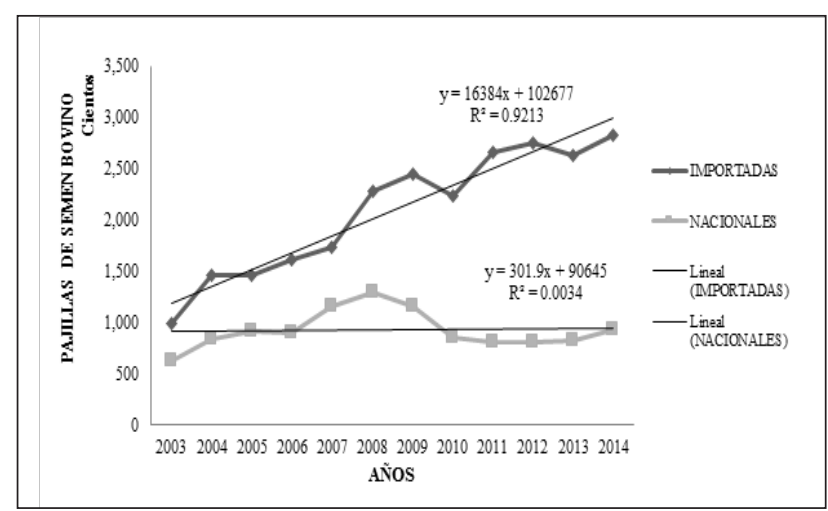

Figura 1. Tendencia de la oferta de pajillas de semen congelado de bovinos importados y nacionales al Perú. Período 2003-2014

El porcentaje del total de pajillas de semen importado y nacional en el período se presentan en la Tabla 3. Se puede observar que en promedio el semen importado representa el $69,31 \%$ y el semen nacional representa el 30,69\%. La relación de pajillas entre lo importado y nacional es de 2,25 a 1 y se debe en primer lugar a la demanda de semen importado por parte del ganadero de crianza intensiva porque las empresas genéticas ofrecen semen con información genética para las características productivas, reproductivas, tipo, genealogía y otros aspectos, y tiene la oportunidad de asegurar la selección de animales, en segundo lugar las empresas distribuidoras de genética emplean gran publicidad, marketing y obsequios para colocar sus productos, en cambio del semen nacional solamente se presenta información de la genealogía y el 
valor genético estimado para la característica de leche; los pequeños y medianos ganaderos usan semen nacional por sus precios accesibles y por sus experiencias prácticas de haber mejorado su producción lechera; además el BNS no tiene centros de distribución en las diferentes zonas ganaderas, lo cual limita el crecimiento en la distribución de pajillas de semen lechero. Todo esto contribuye a que el semen importado llegue más fácilmente al ganadero que el semen nacional, como se observa en la Tabla 3, en el los últimos cinco años se ha incrementado la relación pajillas importadas. Esto representa un reto para el BNS en aumentar su producción y distribución de pajillas semen y así evitar la fuga de divisas.

Tabla 3. Proporción de pajillas de semen de bovino importado y nacional de razas lecheras. Período 2009-2014

\begin{tabular}{cccc}
\hline Año & Importado \% & Nacional \% & Total \\
\hline 2003 & 61.24 & 38.76 & 160865 \\
2004 & 63.29 & 36.71 & 229720 \\
2005 & 61.58 & 38.42 & 238413 \\
2006 & 64.03 & 35.97 & 251359 \\
2007 & 59.94 & 40.06 & 289541 \\
2008 & 63.78 & 36.22 & 357525 \\
2009 & 68.06 & 31.94 & 360498 \\
2010 & 72.53 & 27.47 & 308748 \\
2011 & 76.61 & 23.39 & 346600 \\
2012 & 77.20 & 22.80 & 356535 \\
2013 & 76.14 & 23.86 & 345852 \\
2014 & 75.43 & 24.57 & 375713 \\
\hline Total & 69.31 & 30.69 & 3621369 \\
\hline
\end{tabular}

\section{Cantidad de pajillas por procedencia de continente y país}

Los porcentajes de las cantidades de pajillas importadas son mostrados en la Figura 2. Se observa que la mayor cantidad de semen importado provino de América (Estados Unidos, Canadá, Brasil), con porcentajes anuales oscilando entre el 74\% y 95\%, el año 2014 tuvo el mayor porcentaje $(95,6 \%)$ con un total de 270861 pajillas. Europa ha sido el segundo continente que ha proveído de semen congelado, con variaciones anuales entre $4,4 \%$ a $25,7 \%$, el año 2010 presento la mayor cantidad con 12550 pajillas y finalmente Oceanía que su aporte ha sido muy bajo, con porcentajes anuales inferiores al 1,5\% y solo en un período de 8 años y desde el año 2011 no se han efectuado importaciones, probablemente por la poca demanda de sus pajillas en el país.

En la Figura 3 se muestra el porcentaje de importación por procedencia de país, Estados Unidos y Canadá presentaron los mayores porcentajes de importación $66,89 \%$ y $18,95 \%$ respectivamente, confirmando que son los líderes en el mercado mundial de genética bovina (United Nation Statistics Division, 2014). El 14,16\% restante corresponde a 10 países de los tres continentes. Italia, Suiza, España y Holanda presentaron porcentajes mayores a $1 \%$. Y el resto de países presentan menores porcentajes a $1 \%$.

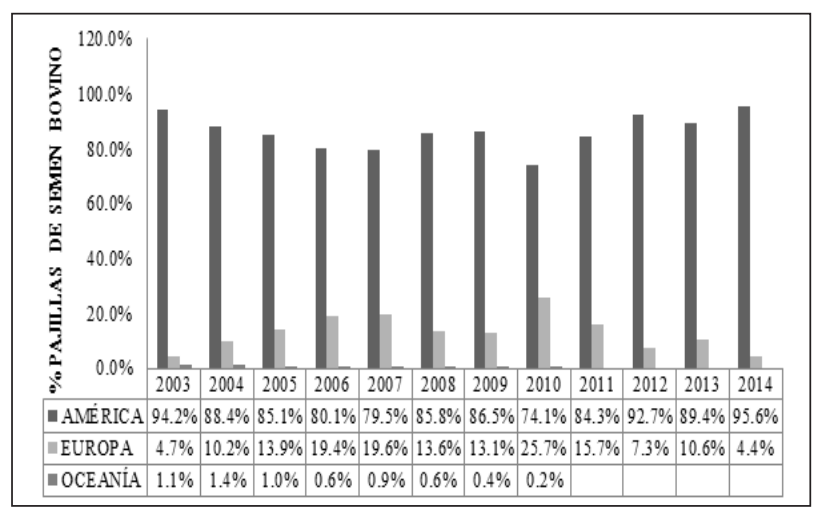

Figura 2. Porcentajes de las pajillas de semen congelado de bovinos lecheros importados por continente al Perú. Período 2003-2014

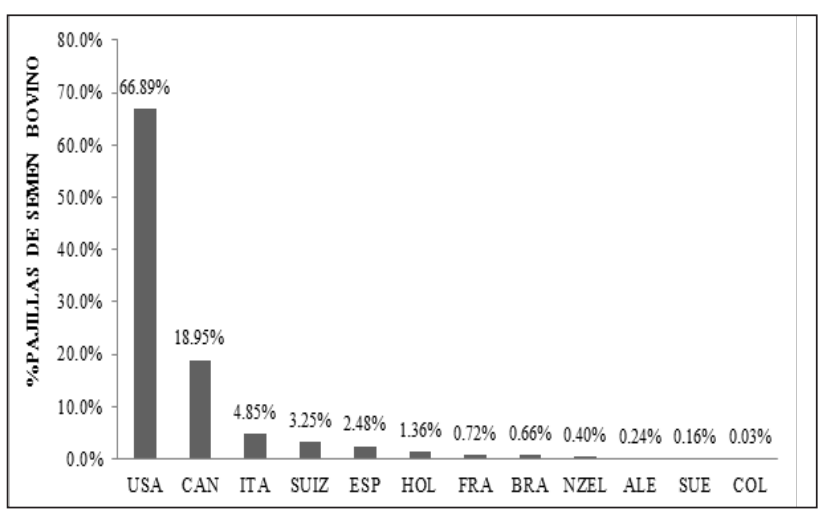

Figura 3. Porcentajes de las pajillas de semen congelado de bovinos lecheros importados por país al Perú. Período 2003-2014

\section{Distribución de pajillas nacionales por región geográfica}

En la Figura 4 se puede observar que la mayor distribución de pajillas nacionales se realizó entre la Costa y la sierra. La región costa tuvo porcentajes de pajillas entre $48 \%$ a $59 \%$, debido a que existe una mayor demanda de genética lechera vía semen congelado por ubicarse las Cuencas Lecheras de mayor importancia como son: Lima y La Libertad, con crianzas intensivas de alta producción lechera. Para la región Sierra, la cantidad de pajillas ofertadas estuvo en un rango de $32 \%$ a $48 \%$; asimismo en esta región las principales Cuencas Lecheras son: Arequipa, Cajamarca y Puno, donde se cría bajo el sistema semi-intensivo. Según el censo del 2012 (INEI, 2016) indica que Cajamarca, Puno, Ayacucho y Cusco concentran el 42\% del ganado vacuno, lo cual brinda la oportunidad de introducir las técnicas reproductivas como la Inseminación Artificial y favorecer el uso de semen congelado; y por último en la Selva, el rango para esta región fue de $2 \%$ a $7 \%$ donde el Banco Nacional de Semen no tiene un mercado considerable pero distribuye material genético especializado para trópico: raza Gyr lechero. En la selva, el uso de la inseminación artificial no es tan difundido como en las otras regiones, empleando mayormente la monta natural, además que existe una venta de semen congelado ilegal que ingresa por 
la frontera de Colombia y Brasil compitiendo con el semen nacional. (Salinas, 2016).

\section{Distribución de pajillas importadas y nacionales por razas}

Las 15 razas lecheras importadas al país se muestran en la Tabla 4, se presenta el número de pajillas total por raza y el total de reproductores por raza. La raza Holstein fue la que predominó con $68 \%$, determinando su importancia en la ganadería lechera nacional; seguida de la raza Brown Swiss con $25 \%$, la cual tiene demanda en la costa, pero principalmente es solicitada en la sierra del país; la raza Jersey representa el $4 \%$ con menor oferta, empleada en algunas ganaderías al norte y al sur del país. El 3\% restante pertenece a otras razas lecheras de menor explotación. Cárdenas (2010) señala que en nuestro país más del 80\% de ganado vacuno es criollo y se aparea con bovinos de valor genético desconocido, por esta razón el ganadero nacional en busca de mejores biotipos de animales con buena genética lechera, introduce nuevas razas para determinar si se adapta a su ambiente de crianza. Las razas lecheras con menor número de pajillas que fueron importadas durante el período, muchas de ellas son para condiciones extensivas, para sierra y trópico, siendo la de mayor porcentaje Gyr lechero, raza que predomina en la selva por su rusticidad y su adaptación al clima tropical. Se debe de tener en cuenta que muchas razas que se importan son utilizadas para cruzamientos de doble propósito, como la raza Simmental, Normando, Pardo Alpina y la Gyr lechero que también se emplea para producción de carne.

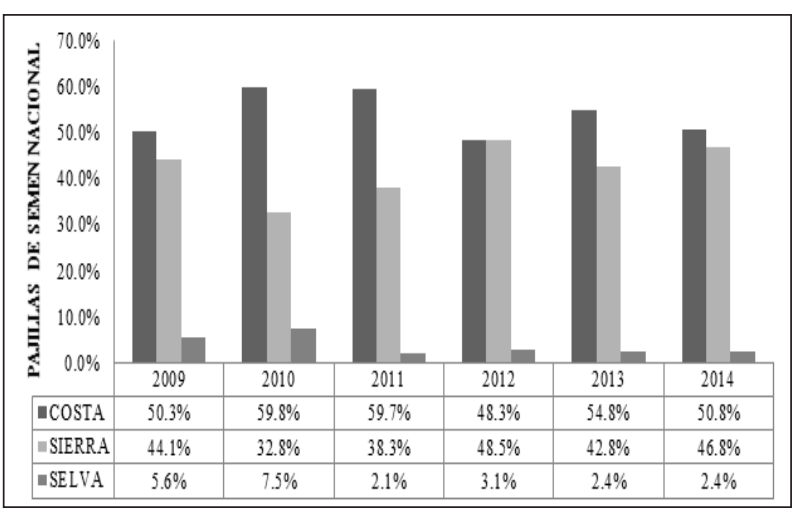

Figura 4. Porcentajes de las pajillas de semen congelado de bovinos lecheros nacionales distribuidos por región. Período 2009-2014

El uso del semen nacional de toros jóvenes registrados, de pedigree provenientes del BNS garantiza al ganadero una genética de calidad. En la Figura 5 se muestra la distribución porcentual de pajillas del BNS por raza, las razas con mayores porcentajes fueron la Holstein con $46 \%$, y Brown Swiss con $41 \%$. Estas dos razas tienen una fuerte presencia en las crianzas tecnificadas del país. Además estas razas se usan para cruzamiento con ganado criollo para mejorar la producción lechera. La raza Holstein se usa por su volumen de producción en sistemas intensivos de la costa y la raza Brown Swiss por su porcentaje de sólidos totales en la leche, además de mejorar la producción de carne y tener mejor adaptación a la crianza semi-intensiva de la zona alto andinas. Las razas de doble propósito como Simmental y Gyr lechero ocupan el tercer y quinto puesto respectivamente solicitadas mayormente en la región sierra y selva. La raza Jersey no tiene mucha explotación en el país, son muy pocas las ganaderías que mantienen esta raza pura, las otras razas fueron destinadas para cruzamiento con ganado criollo por su porcentaje de grasa y tamaño.

Tabla 4. Número de pajillas de semen bovino distribuidas por razas y el número de toros importados al Perú. Período 2003-2014

\begin{tabular}{lrrrr}
\hline \multicolumn{1}{c}{ Raza } & Pajillas & \multicolumn{1}{c}{$\%$} & Toros & \multicolumn{1}{c}{$\%$} \\
\hline Holstein & 1711156 & 68,17 & 3727 & 64,65 \\
Brown Swiss & 634887 & 25,29 & 1320 & 22,90 \\
Jersey & 96444 & 3,84 & 484 & 8,40 \\
Gyr Lechero & 24085 & 0,96 & 58 & 1,01 \\
Pardo Alpina & 9600 & 0,38 & 39 & 0,68 \\
Braunvieh & 9580 & 0,38 & 41 & 0,71 \\
Simmental & 7478 & 0,30 & 30 & 0,52 \\
Montbeliarde & 6700 & 0,27 & 23 & 0,40 \\
Brune & 3380 & 0,13 & 14 & 0,24 \\
Normando & 3270 & 0,13 & 9 & 0,16 \\
Holstein Rojo & 1399 & 0,06 & 8 & 0,14 \\
Rojo Sueco & 1080 & 0,04 & 7 & 0,12 \\
Milking Shorton & 530 & 0,02 & 3 & 0,05 \\
Ayshire & 290 & 0,01 & 1 & 0,02 \\
Abondance & 200 & 0,01 & 1 & 0,02 \\
\hline Total & 2510079 & 100 & 5765 & 100 \\
\hline
\end{tabular}

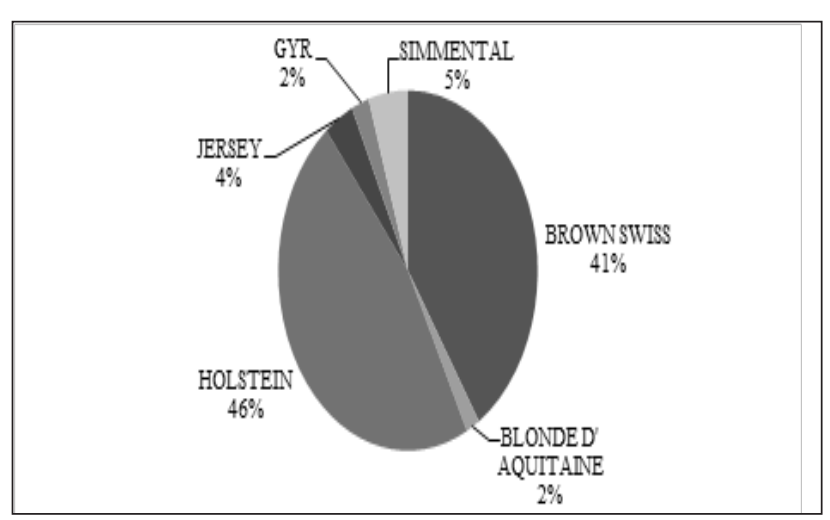

Figura 5. Porcentajes de pajillas de semen congelado de bovinos lecheros nacionales por raza en el Perú. Período 2009-2014

\section{Oferta de pajillas de semen por empresas genéticas}

En la Figura 6 se muestra la distribución de pajillas importadas por empresa genética, ubicadas en América del norte y Europa. ALTA GENETICS (2017) fue la empresa que exportó mayor número de pajillas al país con un total del $21,8 \%$, se originó de la fundación de Carnation Farms, Wisconsin-USA, en 1910, en el año 
2000 expande a 85 distribuidores al por mayor en todo el mundo, en el Perú su representante es Gloria S.A. y tiene una estrecha relación con los ganaderos por el acopio de leche a nivel nacional. SELECT SIRES (2017), ofertó el $16,9 \%$, empresa formada en 1961 por cuatro cooperativas ganaderas de Ohio, Illinois y Kentucky, en los años 2000 extendió su mercado a Europa, África, Asia y Oceanía, y en el 2011, fundó Select Sires do Brasil, subsidiaria y distribuidora en América Latina. COOPERATIVE RESOURCES INTERNATIONAL participó con 13,5\%, empresa establecida en 1993, pero con orígenes en 1920, y que actualmente distribuye semen a más de 60 países teniendo gran demanda en los países de América Latina y Europa. El resto de casas genéticas oscilan entre 0,03\% y $12,7 \%$. De Europa, la empresa comercial con mayor porcentaje de importación fue SWISSGENETICS (2017) de Suiza con $28,5 \%$, representada en más de 80 países y con distribuidores en toda Sudamérica, seguido por ABEREKIN de España con el 17,5\%, en el año 2015 contaba con más de 300 sementales, 50 toros probados al año, 200000 hembras inseminadas y con más de 50 países de los cinco continentes que compran su genética y SEMENZOO principal empresa genética proveniente de Italia con $14,7 \%$. El resto de casas comerciales oscilan entre $0,2 \%$ y $11,6 \%$. Cárdenas, (2010) concluye que el ganadero nacional busca aumentar la calidad productiva de su hato lechero por ello insemina sus vacas con semen importado proveniente de las mejores o más populares empresas genéticas de América y Europa.

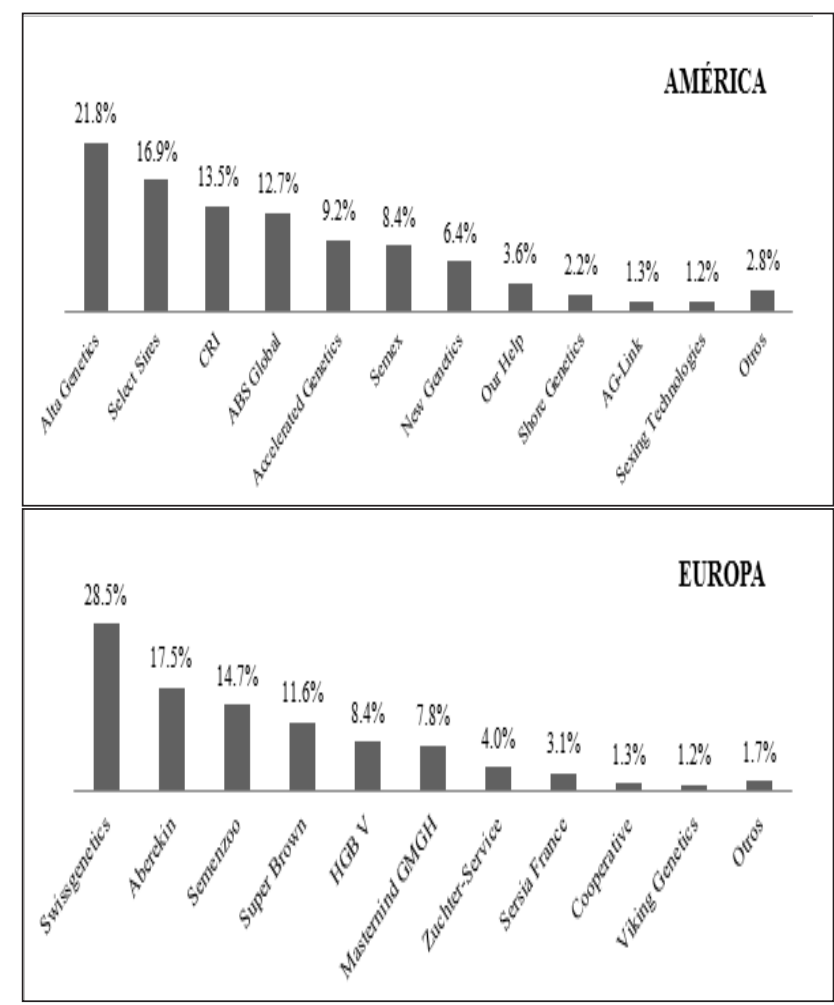

Figura 6. Porcentaje de las pajillas de bovinos lecheros por casas genéticas de América y Europa importadas al Perú. Período 2003-2014

\section{Balance de la oferta y demanda estimada para el 2012}

De la Tabla 1 obtenemos la cantidad de vacas probables a ser servidas en el año 2012, en total 2911480 animales. En una crianza de vacunos lecheros se puede preñar a una vaca con un promedio de 2 a 5 servicios por concepción, dependiendo de la región en la que se encuentre el hato y el sistema de crianza. Si todas las vacas lecheras fueran inseminadas y se usará 2.4 pajillas por preñez, para el número de animales aptos se necesitarían 6987552 pajillas de semen. Las pajillas de semen ofertado para el mismo año fue de 356535 y esta cantidad solo representa el 5,1\% de la probable demanda. Esto indica que la oferta de semen congelado importado y nacional tiene una gran oportunidad para crecer y los distribuidores de ofrecer al ganadero un material genético de calidad que satisfaga sus necesidades.

Debido a esta falta de oferta en las zonas ganaderas, en estos últimos años han surgido nuevas empresas genéticas privadas en Arequipa o Puno que ofertan semen sin ningún control o supervisión por parte del estado. Además, es necesario enfatizar que la falta de vías acceso a las comunidades y zonas ganaderas, dificulta la distribución del material genético, del nitrógeno líquido para su conservación y de los servicios de los técnicos y profesionales en inseminación artificial. Todo esto unido a la falta de gestión de las regiones para elaborar proyectos de mejoramiento animal en sus municipios, conllevan al menor uso de pajillas se semen congelado, el cual si fuera seleccionado adecuadamente para mejorar la producción de leche, nos llevaría a mejorar la condición del ganadero y por ende desarrollar la ganadería nacional.

\section{Conclusiones}

La oferta de pajillas de semen bovino lechero importado es mayor que la oferta de semen nacional en una relación de 2,25 a 1. El crecimiento de la oferta de semen importado es continuo y mayor que la oferta de pajillas de semen bovino nacional, 11,1\% comparado con 4,9\%, incrementándose la brecha en los 12 años de estudio. De Estados Unidos y Canadá se importa la mayor cantidad de pajillas de semen bovino lechero al Perú. La Costa y Sierra fueron las regiones con mayor comercialización de semen nacional en el país. Las razas Holstein, Brown Swiss y Jersey son las principales razas que se ofertan en el país. Las empresas genéticas comerciales con mayor aporte de pajillas fueron: Alta Genetics (USA) proveniente de América del norte y Swissgenetics (Suiza) proveniente de Europa. La oferta de semen importado y nacional en el país cubre la necesidad de solo el 5,1\% de la población de vacas aptas para servicio, lo cual brinda una gran oportunidad para desarrollar este mercado.

\section{Literatura citada}

Aberekin. 2015. Crónicas Ganaderas-Aberekin. Recuperado de: https://issuu.com/aberekin1985/docs/ cr_nicas_ganaderas_35 
ALTA GENETIS. 2017. Todo sobre Mejoramiento y Genética. Colección de artículos. Recuperado de: http://web.altagenetics.com/espanol/Home/AllAbout/ Mejoramiento-y-Genetica.html

Cabrera, P. y Pantoja, C. 2012. Viabilidad espermática e integridad del acrosoma en semen congelado de toros nacionales. Rev Inv Vet Perú 23(2): 192-200.

Cárdenas, M. 2010. Evaluación de las importaciones de Semen de Bovino al Perú en el Período 2003-2008. (Tesis de Ing. Zootecnista. Lima). Universidad Nacional Agraria La Molina, Lima, Perú.

CRI (Cooperative Resources International). 2017. About CRI . Recuperado de: http://cri.crinet.com/

Cunliffe, D. 1990. Anaálisis de la producción y distribución del semen congelado nacional. Su uso e impacto entre 1982 y 1986. (Tesis de Ing. Zootecnista). Universidad Nacional Agraria La Molina, Lima, Perú.

Etcheverry, M. 2009. Exportación de genética bovina: Diagnóstico de situación. Fortalezas y debilidades para competir en el mercado internacional. Argentina Recuperado de: http://www.produccion-animal.com.ar/ informacion tecnica/comercializacion/55exportacion genetica bovina.pdf

SENASA. 2014. Expedientes físicos de las importaciones de dosis de semen 2009-2014.

Funk, DA. 2006. Major advances in globalization and consolidation of the artificial Insemination Industry. Journal of Dairy Science 89:1362-1368.

Heise, A. 2012. Artificial Insemination in Veterinary Science, A Bird's-Eye View of Veterinary Medicine, ISBN: 978-953-51-0031-7: 17-33.

INIE (Instituto Nacional de Estadística e Informática). 2016. IV Censo Agropecuario 2012. Perú. Recuperado de: http://censos.inei.gob.pe/cenagro/tabulados/

Mellisho, E.; Cabrera, P.;Shigueru, S. 2003. Parámetros reproductivos de vacas Holstein en el periodo 19441997 en Santa Rita de Sihuas - Arequipa. Revista Anales Cientificos 55(2):150-161.

Ortiz, D. 2006. Índices reproductivos del ganado vacuno en la cuenca lechera de Lima (Tesis de Médico Veterinario). Universidad Nacional Mayor de San Marcos, Lima, Perú.

Pallete AE. 2001. Evaluación y selección de toros lecheros. Rev. Investig. Vet. Perú 12(2): 150-160.

Salinas J. 2016. Oferta y valoración genética en leche $y$ carne de semen bovino importado y nacional en el Perú 2009-2014 (Tesis de Ing. Zootecnista. Lima). Universidad Nacional Agraria La Molina, Lima, Perú.

United Nation Statistics Division. 2014. UNDATA Statistical Databases. USA. [Internet], [3 Febrero 2017]. Disponible en hppt://data.un.org/Data.aspx?q= semen $\& \mathrm{~d}=$ ComTrade $\& \mathrm{f}=$ = $11 \mathrm{Code} \% 3^{\mathrm{a}} 6 \% 3 \mathrm{bcmdCode}$ $\% 3^{\mathrm{a}} 051110$

SELECT SIRES. 2017. About us and career opportunities. Recuperado de: http://www.selectsires.com/aboutus/ menu.html?version $=20160420$

SWISSGENETICS. 2017. About Swissgenetics. Recuperado de: http://www.swissgenetics.com/ 